MELO, P.C.T.; VILELA, N.J. Desafios e perspectivas para a cadeia brasileira do tomate para processamento industrial. Horticultura Brasileira, Brasília, v.23, n.1, p.154-157, jan.-mar. 2005.

\title{
Desafios e perspectivas para a cadeia brasileira do tomate para processamento industrial
}

\author{
Paulo César T. de Melo ${ }^{1}$; Nirlene Junqueira Vilela ${ }^{2}$
}

${ }^{1}$ USP, ESALQ, Depto. Produção Vegetal, C. Postal 09, 13418-900 Piracicaba-SP; E-mail: pctmelo@esalq.br; ${ }^{2}$ Embrapa Hortaliças, C. Postal 218, 70359-970 Brasília-DF; E-mail: nirlene@cnph.embrapa.br

\section{RESUMO}

Este trabalho teve como principal objetivo descrever alguns dos desafios para maximização da eficiência técnica e socioeconômica da cadeia do tomate para processamento industrial no Brasil. Na década de 1990 observou-se um expressivo desempenho deste setor. Entretanto, no âmbito dos sistemas de produção, observam-se uma série de fatores limitantes à otimização da produção. Dentre esses, cultivares inadequadas à colheita mecanizada e suscetíveis às doenças e pragas que depreciam a qualidade industrial dos frutos, causando quebra na relação matéria prima/massa processada. Ocasionalmente, observam-se ocorrência de fungos na polpa concentra$\mathrm{da}$, extratos e em outros derivados, que poderiam ser evitados com manejo cultural, como maior eficiência das técnicas de irrigação (sistema convencional com pivô central e irrigação por gotejamento), níveis de adubação, rotação de cultivo, preparo do solo e dos canteiros adequados ao transplante e à colheita mecanizados, controle de plantas daninhas e manejo ecológico de pragas e doenças.

Palavras-chave: Lycopersicon esculentum, cultivares, manejo cultural, qualidades nutracêuticas, processamento.

\author{
ABSTRACT \\ Some challenges for the Brazilian chain of processing \\ tomatoes
}

The purpose of this work is to provide information about technological problems that constitute challenges to the maximization of technical and the economic efficiency of the Brazilian chain of tomato processing. In the 90 's the Brazilian chain of the processing tomato showed expressive performance. However, there are several factors involved in the tomato production systems that still impair the optimization of the processing tomato production. Among those factors we detected not well adapted tomato cvs. to mechanical harvest besides being susceptible to diseases and insects, depreciating the fruits quality for processing causing decline indexes in the relationship matter/ processed products. In addition, the presence of fungus was observed in the concentrated pulp, tomato extracts and in other tomato derived products. These problems could be solved through better cultural practices, including better irrigation techniques (conventional system with central pivot and drip irrigation), fertilizer levels, culture rotation, more adequate systems in the preparation of transplant and mechanized harvest, better weeds control and integrated pest and disease management.

Palavras-chave: Lycopersicon esculentum, cultivar, growing practices, nutraceutics, processing products.

\section{(Recebido para publicação em 15 de dezembro de 2003 e aceito em 28 de outubro de 2004)}

$\mathrm{N}_{\mathrm{p}}^{\mathrm{a}}$ América do Sul, o Brasil lidera a produção de tomate para processamento industrial, sendo o maior mercado consumidor de seus derivados industrializados. Entretanto, no contexto mundial, o país tem uma participação de apenas $5,5 \%$ da produção total de tomate para processamento industrial (23,7 milhões de toneladas em 2001) e a exportação de derivados industrializados não é significativa (23,6 mil toneladas em 2000).

A produção de tomate para transformação industrial nos últimos cinco anos foi de 1 milhão de toneladas. Entre 1990 e 2001 o rendimento médio passou de 34 para 75 t/ha, respectivamente. O notável aumento de produtividade (120\%), no período, deve-se basicamente a dois fatores: a) maior concentração de produção em novas fronteiras, como por exemplo o Cerrado (GO e MG), onde as condições edafo-climáticas são mais favoráveis à cultura do tomate rasteiro do que a das outras zonas tradicionais de cultivo do país e, b) à expansão do uso de híbridos com alto potencial produtivo. Mesmo com os significativos avanços observados na cadeia produtiva, ainda existem entraves tecnológicos a serem solucionados para permitir maior competitividade (Vilela et al., 2001). Dessa forma é de fundamental importância o conhecimento dos obstáculos existentes nos diversos segmentos da cadeia produtiva e, principalmente, das demandas das indústrias por soluções tecnológicas.

A indicação de gargalos tecnológicos na cadeia produtiva e levantamento de discussões acerca dos desafios apresentados, podem servir como subsídio para a orientação de trabalhos de instituições de pesquisa e outras vinculadas ao de- senvolvimento do agronegócio.

Este trabalho teve como principal objetivo expor algumas observações sobre problemas tecnológicos que ainda afetam a eficiência técnica e econômica da cadeia do tomate para processamento industrial do Brasil.

\section{MATERIAL E MÉTODOS}

As observações foram realizadas através de visitas técnicas às áreas de produção de tomate para processamento industrial e às agroindústrias de processamento localizadas no estado de Goiás, em 2001. Além das entrevistas com produtoras e observações in loco, foram feitas inferências utilizando-se os materiais fornecidos pelas agroindústrias processadoras e artigos técnico-científicos publicados sobre o assunto em referência. 


\section{RESULTADOS E DISCUSSÃO}

O futuro das empresas está orientado pelo trinômio básico da competitividade, ou seja, produção sustentável, minimização de custos e otimização da qualidade. Para se alcançar esses parâmetros, as condições de máxima eficiência técnica e econômica são exigidas pela cadeia produtiva do tomate para processamento, principalmente, nos setores à montante, no setor produtivo e de processamento. Nesse último, o processamento de matéria-prima com alto padrão de qualidade é de fundamental importância, sobretudo com relação à acidez, sólidos e viscosidade. Esses parâmetros exercem marcada influência sobre os custos de processamento e a qualidade final dos produtos.

\section{Melhoramento genético e manejo} cultural

Os programas de melhoramento genético de instituições oficiais de pesquisa do país têm, historicamente, contribuído para o progresso da cultura do tomate para processamento. A prioridade desses programas tem sido a obtenção de cultivares mais bem adaptados às condições climáticas das principais regiões de cultivo, resistência e/ou tolerância a doenças e a pragas limitantes e a melhoria de características agronômicas e indústrias (Kurosawa, 1991; Melo, 1991; Melo, 1998; Menezes e Wanderley, 1991; Nagai, 1990).

Observa-se que, desde os primeiros anos da década de 90 , os programas de pesquisa e desenvolvimento relacionados ao melhoramento genético e ao manejo da cultura do tomate industrial no país vêm sofrendo uma significativa redução de atividades. Neste período as inversões governamentais em pesquisa e desenvolvimento decresceram significativamente em comparação aos anos 80, limitando-se a privilegiar áreas estratégicas como a biotecnologia e genética genômica. Por outro lado, as empresas de sementes transnacionais que operam no país vêm restringindo suas atividades de pesquisa no Brasil, limitando-se a realizar atividades de adaptação de híbridos obtidos em outros países.

Muitas demandas dos setores produtivo e de processamento para solução de problemas tecnológicos nos sistemas de produção não foram atendidas, constituindo-se em importantes desafios para a pesquisa, tais como:

\section{Cultivares para colheita mecani-} zada

Em todas as regiões de cultivo de tomate industrial do mundo, a introdução da colheita mecanizada foi precedida por ajustes na escolha de cultivares e nas práticas de manejo cultural. Além disso, houve necessidade de se adequar as estruturas das fábricas para recepção de matéria-prima colhida mecanicamente. Isso implicou em mudanças na atracação dos caminhões para descarga do tomate, no sistema de lavagem com duchas e no processo de seleção na linha de ingresso da matéria-prima. Na maioria das regiões brasileiras produtoras de tomate a colheita manual foi substituída pela colheita mecanizada em decorrência da complexidade operacional diante das leis do trabalho. Entretanto, os altos custos das máquinas e das peças de reposição importadas oneram os custos de produção e envolvem, em geral, um longo período para se obter o retorno dos investimentos.

Por outro lado, observa-se na região dos Cerrados que os sistemas de produção de plantio direto (semeio ou transplantio de mudas diretamente na palhada do milho, sorgo, ou milheto) avançam, em termos de área plantada. Sob o ponto de vista econômicoambiental esses sistemas apresentam vantagens relativas. Entretanto, nota-se que as máquinas e equipamentos empregados, ainda não estão totalmente adaptados para esses sistemas. Em geral, os produtores fazem o plantio direto com máquinas pesadas desde o preparo da área até a colheita, o que de certo modo, contribui para a compactação do solo. As máquinas e equipamentos são as mesmas utilizadas nos sistemas convencionais, incompatíveis com a lógica dos sistemas de plantio direto.

A utilização de híbridos já consolidada, em geral, tem um melhor balanço de sólidos e viscosidade, particularmente importante durante o processamento final de pasta de tomate. Além disso, apresentam as características requeridas pelas indústrias, como melhor uniformidade, cor, firmeza, forma, espessura da parede do fruto e baixo índice de defeitos. Em 2003, o híbrido mais plantado ocupou mais de 5.500 hectares.

A introdução de híbridos com características apropriadas à colheita mecanizada tem sido baseada nos resultados de ensaios de competição de variedades ou de testes de parcelas simples conduzidos por algumas indústrias e pelas empresas de sementes. Diante deste fato, verificase que existe uma grande oportunidade de pesquisa para as instituições públicas e privadas do Brasil, para desenvolvimento de novas cultivares adaptadas às condições agroecológicas do Cerrado.

$\mathrm{Na}$ atual conjuntura brasileira de processamento de tomate, a ênfase deveria ser dada na identificação ou desenvolvimento de cultivares do tipo "multiuso", isto é, com versatilidade de uso industrial prestando-se à fabricação de pasta concentrada, cubeteado ou triturado.

Na seleção de combinações híbridas promissoras para colheita mecanizada, devem ser avaliados a concentração de maturação, o potencial produtivo, o tamanho da rama que deve ser mediano, a cobertura dos frutos, a capacidade de permanência dos frutos na planta em condições de campo, a firmeza que permita o transporte dos frutos a granel e o índice de retenção de pedúnculo no fruto. Outras características inerentes às cultivares que se destinam ao processamento industrial como o teor de sólidos solúveis ( ${ }^{\circ}$ Brix acima de 5,0 ), coloração vermelho-intensa (externa e interna), pericarpo espesso, inserção peduncular pequena, ausência de defeitos (ombro amarelo, coração negro, zippering, split setting) entre outros, devem ser avaliados de forma criteriosa.

O desenvolvimento de cultivares para processamento do "tomate seco" constitui um importante nicho para os trabalhos de pesquisa. O tomate tipo "seco" vem apresentando tendências de franca expansão de mercado. No Brasil, este tipo de produto, em maior parte, tem sido importado de outros países. Atualmente, não existem cultivares adequadas para produção de tomate seco. As cultivares utilizadas têm grande quantidade de água na polpa, o que exige muito tempo (em média 12 horas) para desidratação completa. A fabricação de tomate seco tem sido realizada 
por pequenas empresas que ainda utilizam equipamentos artesanais.

\section{Doenças e pragas}

Em geral, a cultura do tomate, nas regiões tropicais e subtropicais, é afetada por expressivas quebras de rendimento e depreciação da qualidade de matéria-prima, em razão de ocorrência de doenças, pragas e estresses abióticos. Nas condições do agroecossistema do Cerrado, são prioritárias as pesquisas sobre doenças como mancha-bacteriana, pinta-bacteriana, begomoviroses e nematóides das galhas. Entre as pragas de maior preocupação na tomaticultura destacam-se a mosca-branca e a traçado-tomateiro.

O controle das doenças e pragas em referência, com utilização exclusiva de agroquímicos tem contribuído para a degradação dos ecossistemas, pondo em risco a saúde humana em vista do acúmulo de resíduos tóxicos. $\mathrm{O}$ desenvolvimento de genótipos com resistência genética aos patógenos, além de ser a solução mais racional do ponto de vista ambiental, pode proporcionar o crescimento da agroindústria do tomate no Cerrado nas próximas décadas, maximizando a eficiência dos fatores econômicos e ambientais.

\section{Otimização do manejo cultural}

O manejo adequado é de fundamental importância para maximizar os rendimentos físicos da produção e melhorar a qualidade da matéria-prima, que contribui para elevar os rendimentos industriais. A utilização de cultivares inadequadas à colheita mecanizada e suscetíveis às doenças e pragas deprecia a qualidade industrial dos frutos, causando quebra na relação matéria-pri$\mathrm{ma} /$ massa processada. Adicionalmente, a ocorrência de fungos na polpa concentrada, extratos de tomate e em outros derivados poderia ser evitada com melhor manejo cultural e maior eficiência das técnicas de irrigação (sistema convencional com pivô central e irrigação por gotejamento). Além da adequação dos níveis de adubação, rotação de cultivo, preparo do solo e dos canteiros para o transplante e colheita mecanizados, controle de plantas daninhas e manejo ecológico de pragas e doenças.

Além da identificação ou desenvolvimento de novas cultivares, é necessá- rio adequar as técnicas de irrigação e fertirrigação, com vistas a obter melhor qualidade do fruto. Técnicas mais eficientes de rotação de cultivos, densidade de plantio vs. adubação (influência na precocidade e na concentração de maturação) devem ser desenvolvidas pela pesquisa, para áreas onde o plantio direto na palha está em franca expansão.

\section{Atributos de qualidade}

A sustentabilidade econômica das indústrias de processamento depende da qualidade da matéria-prima. Os atributos de qualidade da matéria-prima são determinados por diversos fatores que exercem grande influência na fabricação dos diferentes produtos à base de tomate. No Brasil, os dois principais derivados são o extrato concentrado e os molhos prontos obtidos do tomate cubeteado ou triturado. Cada um desses produtos exige atributos diferenciados, em termos de teor de sólidos solúveis (Brix), viscosidade, sabor, acidez, cor, espessura do pericarpo e de facilidade de remoção da pele dos frutos. A qualidade da matéria-prima, em maior parte, determina a qualidade do produto final derivado. É comum observar quebra na relação matéria-prima/massa processada, conseqüente de fungos na polpa concentrada, extratos e outros derivados, causados pela baixa qualidade da matéria-prima para processamento industrial. Para evitar esses problemas recomenda-se à pesquisa o desenvolvimento de técnicas de manejo cultural e irrigação mais eficientes (tanto nos sistemas convencionais com pivot central como por gotejamento), incluindo níveis de adubação, rotação de cultivo, preparo do solo e dos canteiros adequados ao transplante e à colheita mecanizados, controle de plantas daninhas e manejo ecológico de pragas e doenças. Com vistas ao aumento da eficiência técnica e econômica da cadeia produtiva, o conhecimento das demandas por pesquisas na área pós-colheita do tomate industrial deve ser atualizado de forma contínua.

\section{Qualidades nutracêuticas}

Nos últimos anos, o tema "tomate e saúde" tem obtido uma considerável dimensão em todo o mundo e poderá constituir-se num poderoso argumento para alavancar o consumo e a produção de tomate e derivados. Resultados de estudos epidemiológicos conduzidos na União Européia e nos EUA têm sugerido que as propriedades antioxidantes do licopeno e o pigmento carotenóide que dá a cor vermelha ao tomate, são capazes de prevenir diversos tipos de câncer, doenças cardiovasculares e degenerativas. Aparentemente, o licopeno atua retardando ou amenizando os efeitos dos radicais livres, moléculas instáveis que danificam as células sadias do organismo (Giovannuci, 1998).

Especialistas preconizam que o desenvolvimento de cultivares de hortaliças, frutas e cereais com qualidades nutracêuticas reconhecidas pela comunidade científica, constitui um dos principais fatores de redirecionamento da indústria de alimentos em todo o mundo nas próximas décadas (Offord, 1998; Sies e Stahl, 1999). O desenvolvimento de cultivares de tomate para processamento com alto teor de licopeno é uma grande oportunidade de pesquisa no país por se tratar de um tema de real interesse tanto para as indústrias quanto para os consumidores. Ademais, é uma linha de pesquisa inovadora que poderia ser desenvolvida com o apoio do setor agroindustrial do tomate, envolvendo as áreas de melhoramento clássico e/ou a biotecnologia (genética genômica, engenharia genética).

\section{A questão da segurança alimentar}

O tema segurança alimentar deve se converter em fator crítico importante para as empresas no futuro próximo, a exemplo do que já vem ocorrendo na União Européia nos últimos anos. Desse modo, as empresas devem estar dispostas a garantir aos consumidores a segurança de seus processos de transformação industrial, assim como também a segurança da matéria-prima utilizada para produzir pasta ou outro derivado de tomate.

É imperativo que o setor produtivo agrícola e o setor industrial atuem de forma cada vez mais integrada buscando agregar tecnologias com capacidade de elevar a produtividade, em bases sustentáveis, de melhorar a qualidade da matéria-prima e dos produtos acabados e de reduzir custos. Por outro lado, os programas de agricultura sustentável para a tomaticultura industrial, consti- 
tuem atualmente o centro das atenções das empresas processadoras em operação. Portanto, o desenvolvimento e implementação de modelos de agricultura sustentável deverá enfocar a redução dos riscos ambientais e a preservação dos recursos escassos como água e energia elétrica.

$\mathrm{Na}$ atual conjuntura de mercado, a cadeia do tomate industrial vem sendo considerada como eficiente e competitiva. Entretanto, grandes desafios de ordem técnica, econômica e social são observados e, ainda, carecem de esforços de pesquisa por parte das instituições de pesquisa pública e privada. Nesse sentido, destacam-se entre outros, os problemas com os níveis de perdas de tomate, tanto na colheita como na póscolheita; quebra na relação matéria-pri$\mathrm{ma} /$ produto processado; qualidade inferior do produto final devido a problemas fitossanitários da cultura que afetam a qualidade da matéria-prima. Cultivares inadequadas para a colheita mecanizada; desenvolvimento de um programa integrado de pragas e doenças que vêm causando danos econômicos tanto na produção, como na qualidade do produto processado; técnicas mais eficientes de irrigação e manejo cultural; máquinas e equipamentos inadequados à lógica dos sistemas plantio direto. Adicionalmente, urge o atendimento às demandas sociais por geração de cultivares e/ou híbridos com maior conteúdo de licopeno. O maior conteúdo de carotenóides, associado a outros fatores que promovem os padrões de qualidade da matéria-prima e dos produtos derivados, acrescentam valor agregado, contribuindo para elevar a maximização da eficiência técnica e socioeconômica da cadeia produtiva do tomate.

Finalmente, ressaltam-se que as soluções tecnológicas para os problemas que ainda afetam a eficiência técnica e socioeconômica da cadeia produtiva exigem o desenvolvimento de um plano multidisciplinar de pesquisa e experimentação com o efetivo suporte dos setores agrícola e industrial.

\section{AGRADECIMENTOS}

Ao Dr. Leonardo Giordano, pesquisador da Embrapa Hortaliças pelas contribuições e ao Dr. Paulo Bonni, gerente da Coopercentro e Dr. Alessandro Cruvinel, técnico da Unilever Bestfoods pela colaboração neste trabalho.

\section{LITERATURA CITADA}

BARBOSA, V. The processing tomato - growing system under tropical and subtropical conditions: the Brazilian experience. In: INTERNATIONAL CONFERENCE ON THE PROCESSING TOMATO, 1.; INTERNATIONAL SYMPOSIUM ON TROPICAL TOMATO DISEASES, 1., 1996 , Recife. Proceedings... Alexandria: ASHS: IPA, 1997. p.94-97.

GIOVANNUCI, E. Tomato intake and cancer risk a review of the epidemiologic evidence. In: PROCEEDINGS OF THE TOMATO \& HEALTH SEMINAR, 1998, Pamplona. p.69-80.
KUROSAWA, C. Melhoramento genético da cultura do tomateiro visando tolerância e/ou resistência às doenças causadas por bactérias. In: ENCONTRO NACIONAL DE PRODUÇÃO E ABASTECIMENTO DE TOMATE, 2., 1991, Jaboticabal. Palestras... Jaboticabal: UNESPFCAV: SOB: ANDEF: FUNEP, 1991. p.72-80.

MELO, P.C.T. Recursos genéticos e melhoramento do tomateiro industrial no semi-árido brasileiro. In: CONGRESSO BRASILEIRO DE OLERICULTURA, 38., 1998, Petrolina, PE. Melhoramento de hortalicas para o nordeste brasileiro: paineis. Petrolina: EMBRAPA-CPATSA/ SOB, 1998. nao paginado.

MELO, P.C.T. Tendências do melhoramento genético do tomateiro visando mesa e indústria no Brasil. In: ENCONTRO NACIONAL DE PRODUÇÃO E ABASTECIMENTO DE TOMATE, 2., 1991, Jaboticabal. Palestras... Jaboticabal: UNESP-FCAV: SOB: ANDEF: FUNEP, 1991. p.35-46.

MENEZES, D.; WANDERLEY, L.J.G. Progressos e perspectivas do melhoramento genético do tomateiro industrial no nordeste brasileiro. In: ENCONTRO NACIONAL DE PRODUÇÃO E ABASTECIMENTO DE TOMATE, 2., 1991, Jaboticabal. Palestras... Jaboticabal: UNESPFCAV: SOB: ANDEF: FUNEP, 1991. p.47-64.

NAGAI, H. Avanços obtidos com o melhoramento genético do tomate no Brasil. In: ENCONTRO NACIONAL DE PRODUÇÃO E ABASTECIMENTO DE TOMATE, 1., 1990, Viçosa. Anais... Viçosa: UFV: SOB: EPAMIG: EMATER-MG: CEASA-MG, 1990. p.88-107.

OFFORD, E.A. Nutritional and health benefits of tomato products. In: PROCEEDINGS OF THE TOMATO \& HEALTH SEMINAR, 1998, Pamplona. p.5-10.

SIES, H.; STAHL, W. Biovality of lycopene. Acta Horticulturae, v.487, p.389-393, 1999.

VILELA, N.J. Competitividade da cadeia industrial do tomate em Goiás. In: VIEIRA, R.C.M.;TEIXEIRA FILHO, A.R.; OLIVEIRA, A.J.; LOPES, M.R. Cadeias produtivas no Brasil: análise da competitividade. Brasília: Embrapa: Fundação Getúlio Vargas, 2001. 468 p. 